\title{
Identification of hydroacoustic wave sources of ship in motion
}

\author{
Eugeniusz Kozaczka, Prof. \\ Gdansk University of Technology \\ Naval Academy of Gdynia \\ University of Technology and Life Sciences in Bydgoszcz \\ Jacek Domagalski, Ph. D. \\ Naval Academy of Gdynia
}

\begin{abstract}
This paper deals with results of identification tests of acoustic field spectrum of underwater noise generated by ship in motion. The field is connected with acoustic activity of ship mechanisms and devices in operation. Vibration energy generated by the mechanisms and devices is transferred through ship structural elements to surrounding water where it propagates in the form of acoustic waves of a broad band of frequencies. In the publication results of identification tests of underwater noise generated by a ship in motion, are presented.
\end{abstract}

Keywords: Identification; propagation; hydroacoustics

\section{INTRODUCTION}

Every new-built naval ship, after capital repair or modernization work, is subjected to a series of complex tests carried out in testing and measuring trial areas of Polish Navy. In the frame of the tests, a.o., measurements of underwater noise generated by ships are conducted both in stationary and dynamic trial areas. The results of identification of acoustic wave sources, obtained from the tests performed in a stationary trial area have been presented in the previous publication $[7,8,9,10]$.

After the measurements carried out in the stationary trial area, were made measurements of underwater noise generated by a ship in motion. The tests were aimed at confirming the results of identification of acoustic wave sources determined in the stationary trial area (i.e. main engines, ship propellers, shaft lines, electric generating sets), as well as at determining theoretical relationships on the basis of which it would be possible to present frequencies of waves generated by propulsion systems operating at different ship speeds. The below presented results were obtained from the above mentioned complex tests of the ship. During the tests, hydroacoustic field measurements for all operational settings of propulsion systems, were performed. During its service a ship under testing crosses the control and measurement areas about once per two months. Since the complex measurements taken in 2004, the ship in question crossed the ranges 147 times (33 measurements recorded during the complex measurement tests and 114 control tests in service). Hence a vast body of information about noise emitted by the ship to surrounding water, has been collected in archives. In view of the rich amount of data obtained from the tests, only representative results are published in this paper.

During the hydroacoustic tests ships cross twice (with course angle: $180^{\circ}$ and $0^{\circ}$ ) the measurement trial area at set operational parameters of their propulsion systems. The set ship parameters are reached at the distance of $300 \mathrm{~m}$ at least before the trial area and maintained over the distance of $600 \mathrm{~m}$ at least ( $300 \mathrm{~m}$ behind the buoys). Most data were recorded by a hydrophone located $1 \mathrm{~m}$ over the sea bed. The continuous recording of acoustic pressure measurements is made at a distance afore and astern the ship. The information obtained this way makes it possible to characterize underwater disturbances around the ship. In Fig. 1 is shown a schematic picture of the facility for hydroacoustic field control and measurements.

To compare results obtained from measurements performed in dynamic and stationary trial areas the common diagram of the spectra recorded during the trials was prepared as shown in Fig. 2.

As can be clearly observed in the presented spectra, both the noise records are quite similar in the frequency band up to $100[\mathrm{~Hz}$. In this range the underwater noise records were analyzed in detail and compared to each other.

The signals recorded in the trial areas were processed with the use of PULS software. They were appropriately modified by using EXEL calculation sheet to make their presentation more clear. The spectra obtained from the tests are presented in Fig. 3. In the spectra can be observed a series of excitations which repeated during the tests of ship engines both under load and idle running. 


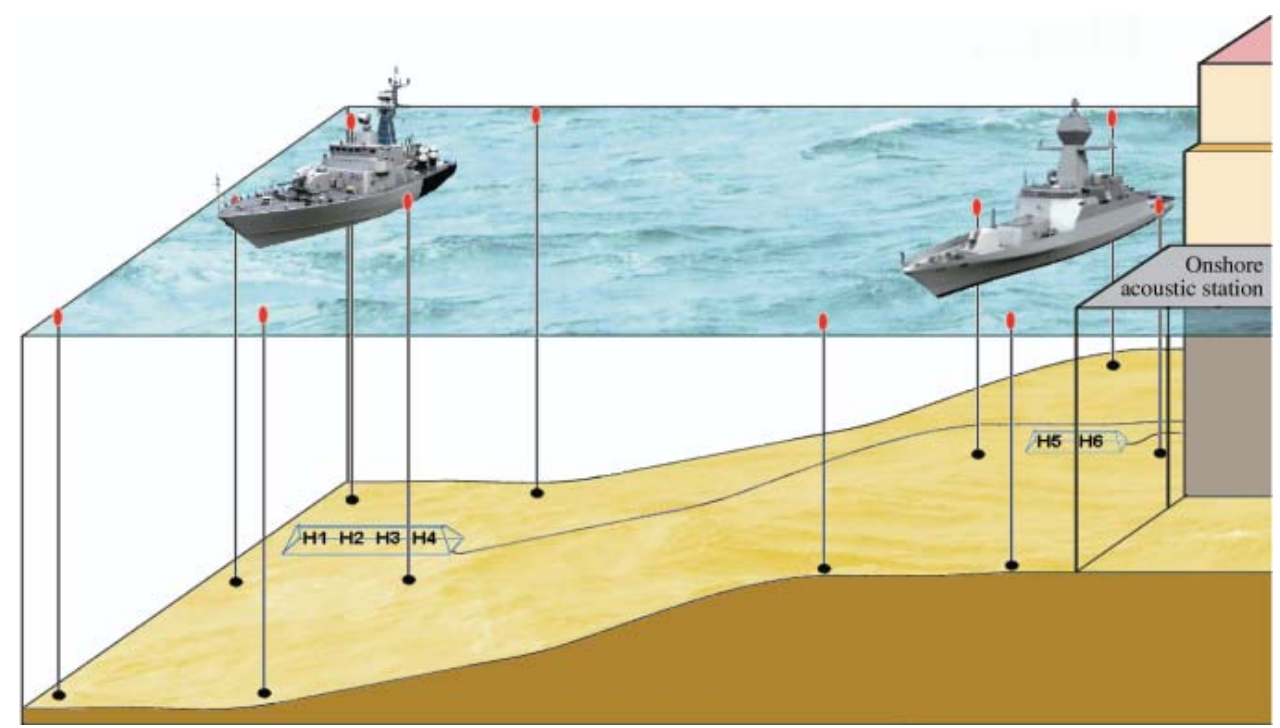

Fig. 1. Schematic picture of a movable trial facility for underwater measurement of acoustic disturbances generated by ship in motion, where: $\mathrm{H1}, \mathrm{H2}, \ldots \mathrm{H6}-$ hydrophones

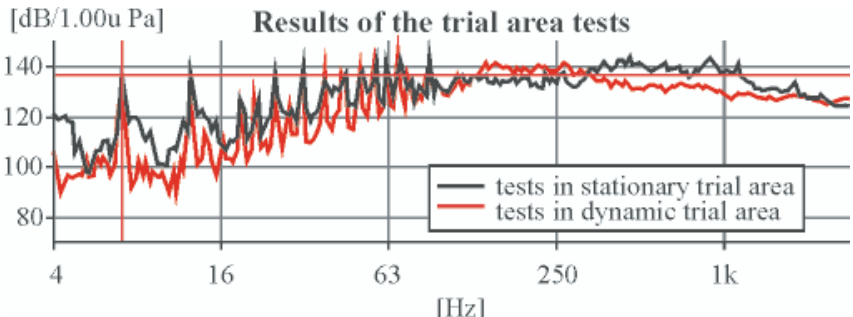

Fig. 2. Acoustic pressure spectra recorded during the tests in dynamic and stationary trial areas

\section{$\mathrm{L}\left[\mathrm{dB}\right.$ re $\left.10^{-6} \mathrm{~Pa}\right] \quad$ Acoustic pressure}

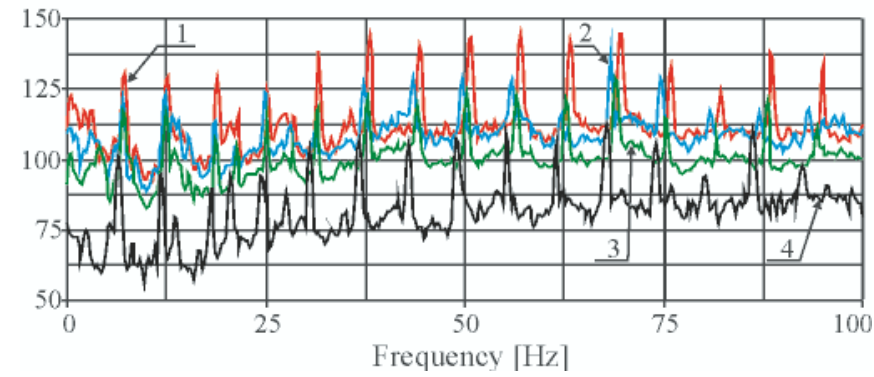

Fig. 3. Underwater noise spectra of the tested ship. Signals recorded at the main engine speed $n=750$ [rpm]. Notation: 1 . the underwater noise spectrum. Tests in stationary trial area (two engines under operation), 2. the underwater noise spectrum (signal suppressed by $10[\mathrm{~dB}]$ ). Tests in stationary trial area (left engine under operation), 3. the underwater noise spectrum (signal suppressed by 20[dB]). Tests in stationary trial area

(right engine under operation), 4. the underwater noise spectrum (signal suppressed by $30[\mathrm{~dB}]$ ). Tests in dynamic trial area (two engines under operation)

When comparing the tests of acoustic field structure of the ship in motion with those performed in standstill it can be observed that in the band up to about $100[\mathrm{~Hz}]$ the noise records are relatively similar.

The identifying was initiated from the analysis of acoustic fiel structure of the ship moving with 4-knot speed. Fig. 4 presents the spectrogram containing changes in acoustic pressure level and distance covered by the ship in function of frequency. The spectrogram is composed of 299 spectra recorded every 312 [ms], at $1 / 24$ octave resolution in the frequency band from $3[\mathrm{~Hz}]$ to $2.818[\mathrm{kHz}]$. The dashed lines mark distances from the ship to the acoustic sensor.

Two distinct zones are seen in the spectrogram. The first zone contains frequencies up to about $100[\mathrm{~Hz}]$. In the zone

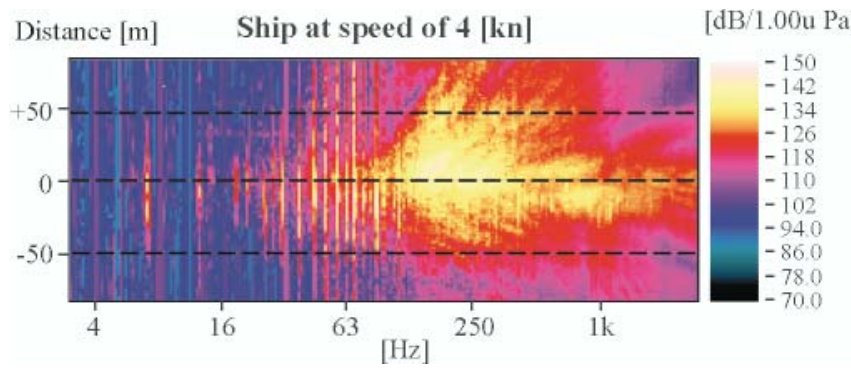

Fig. 4. Acoustic field spectrogram of the ship moving at speed of 4 knots

characteristic components resulting from operation of ship mechanisms can be distinguished. The second zone from $100[\mathrm{~Hz}]$ to $2.8[\mathrm{kHz}]$ contains the continuous spectrum. The spectrum is associated with operation of cavitating screw propeller, turbulent flow through pipelines, water flow around the hull, air flow through fans etc.

To identify in detail the characteristic spectral components appearing in the first zone a spectrogram was prepared with the use of the same filters and settings which were applied during the ship's tests in the stationary trial area. The applied software (as well as the analyzer internal memory) made it possible to record $98.6 \mathrm{~s}$ - time interval of underwater noise of the ship crossing the trial area. The recording time interval made it possible to examine changes in hydroacoustic field of the ship over the distance of about $100 \mathrm{~m}$ before and behind the trial area.

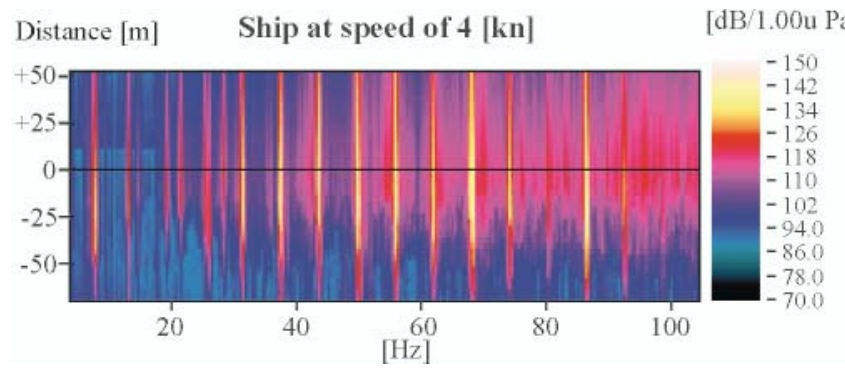

Fig. 5. Acoustic field spectrogram of the ship moving at speed of 4 knots

The spectrogram is consisted of 74 spectra recorded every 1.333 [s] with $0.25 \mathrm{~Hz}$ - resolution in the band up to 100 [Hz]. From the figure was selected the spectrum when the ship's engine room was just over the acoustic sensor (the place is distinguished with black line on the spectrogram). 


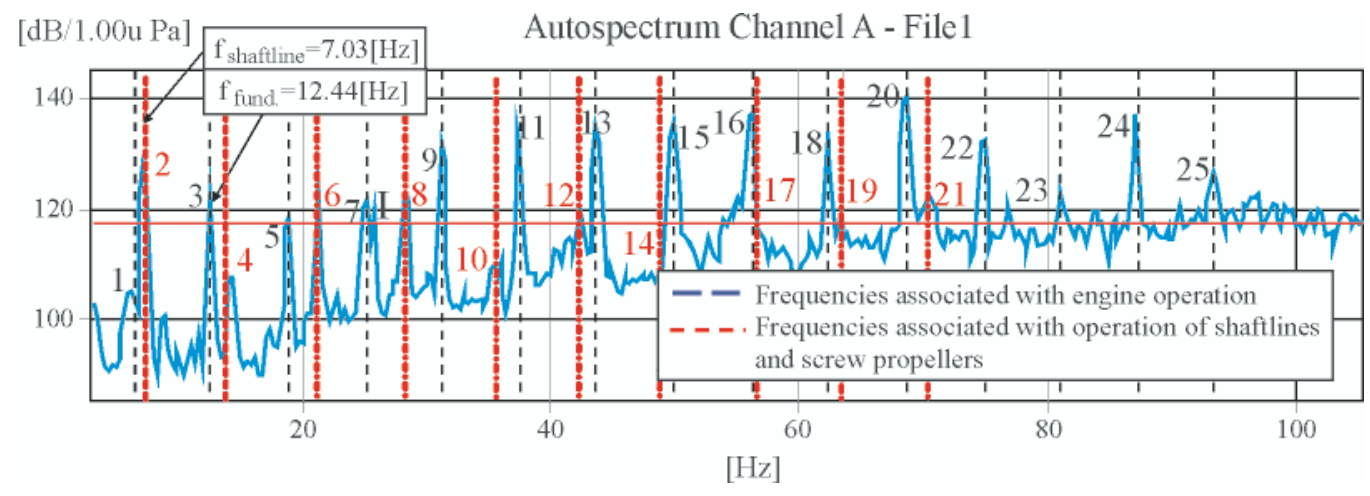

Fig. 6. The acoustic field spectrum of the ship, prepared for the distance ,0” marked in the spectrogram of Fig. 5

In the figure are clearly seen the characteristic components resulting from operation of the main engines, shaft lines and screw propellers, as well as the single red stripe numbered „I" resulting form operation of the electric generating set. Each of the characteristic components is distinguished by a successive number whose green digits stand for components due to operation of the screw propellers and shaft lines, and black digits represent components due to operation of the main engines. The characteristic spectral components are additionally marked with dashed lines as follows: those in blue show frequencies associated with operation of the main engines, and those in black - frequencies associated with operation of the shaft lines and screw propellers.

As observed on the basis of the performed trials the frequencies associated with operation of the propulsion systems can be determined from the following relationships:

1. Frequencies associated with combustion process occurring in main engine cylinders:

- fundamental frequencies of firing in particular cylinders of engines:

$\mathrm{f}_{\mathrm{z} 1}=\mathrm{f}_{\mathrm{o}} \cdot \mathrm{s}$ - fundamental frequency of firing in one cylinder,

$\mathrm{f}_{\mathrm{z} 2}=2 \mathrm{f}_{\mathrm{o}} \cdot \mathrm{s}$ - fundamental frequency of firing in two cylinders,

$\mathrm{f}_{\mathrm{z} 3}=3 \mathrm{f}_{\mathrm{o}} \cdot \mathrm{s}$ - fundamental frequency of firing in three cylinders,

$\mathrm{f}_{\mathrm{z}}=\mathrm{f}_{\mathrm{z} 6}=6 \mathrm{f}_{\mathrm{o}} \cdot \mathrm{s}$ - frequency of firing in six cylinders.

- $2^{\text {nd }}$ harmonic frequencies of firing in engine cylinders: $\mathrm{f}_{\text {IIz1 }}=\mathrm{f}_{\mathrm{z} 1}+\mathrm{f}_{\mathrm{z}}-2^{\text {nd }}$ harmonic frequency of firing in one cylinder,

$\mathrm{f}_{\mathrm{IIz} 2}=\mathrm{f}_{\mathrm{z} 2}+\mathrm{f}_{\mathrm{z}}-2^{\text {nd }}$ harmonic frequency of firing in two cylinders,

$\mathrm{f}_{\mathrm{IIz} 3}=\mathrm{f}_{\mathrm{z} 3}+\mathrm{f}_{\mathrm{z}}-2^{\text {nd }}$ harmonic frequency of firing in three cylinders,

$\mathrm{f}_{\text {IIz6 }}=2 \mathrm{f}_{\mathrm{z}}-2^{\text {nd }}$ harmonic frequency of firing in six cylinders,

- $3^{\text {rd }}$ harmonic frequencies of firing in engine cylinders: $\mathrm{f}_{\text {IIIz! }}=\mathrm{f}_{\mathrm{z} 1}+2 \mathrm{f}_{\mathrm{z}}-3 \mathrm{rd}$ harmonic frequency of firing in one cylinder,

$\mathrm{f}_{\text {IIIz2 }}=\mathrm{f}_{\mathrm{z} 2}+2 \mathrm{f}_{\mathrm{z}}-3 \mathrm{rd}$ harmonic frequency of firing in two cylinders,

$\mathrm{f}_{\text {IIIz3 }}=\mathrm{f}_{\mathrm{zz}}+2 \mathrm{f}_{\mathrm{z}}-3 \mathrm{rd}$ harmonic frequency of firing in three cylinders,

$\mathrm{f}_{\text {IIIz6 }}=3 \mathrm{f}_{\mathrm{z}}-3 \mathrm{rd}$ harmonic frequency of firing in six cylinders.
2. Frequencies associated with rotation of screw propellers: $\mathrm{f}_{\mathrm{s} 1}=\mathrm{f}_{\mathrm{o}} / 1.77$ - fundamental frequency due to operation of one blade of screw propeller,

$\mathrm{f}_{\mathrm{s} 2}=2 \mathrm{f}_{\mathrm{o}} / 1.77$ - fundamental frequency due to operation of two blades of screw propeller,

$\mathrm{f}_{\mathrm{s}}=4 \mathrm{f}_{\mathrm{o}} / 1.77$ - fundamental frequency due to operation of screw propellers.

- $2^{\text {nd }}$ harmonic frequencies associated with operation of screw propellers:

$\mathrm{f}_{\text {IIś1 }}=\mathrm{f}_{\mathrm{o}} / 1.77+\mathrm{f}_{\mathrm{s}}-2^{\text {nd }}$ harmonic frequency due to operation of one blade of screw propeller,

$\mathrm{f}_{\text {IIs } 2}=2 \mathrm{f}_{\mathrm{o}} / 1.77+\mathrm{f}_{\dot{s}}-2^{\text {nd }}$ harmonic frequency due to operation of two blades of screw propeller,

$\mathrm{f}_{\text {IIs }}=4 \mathrm{f}_{\mathrm{o}} / 1.77+\mathrm{f}_{\mathrm{s}}-2^{\text {nd }}$ harmonic frequency due to operation of screw propeller,

- $3^{\text {rd }}$ harmonic frequencies associated with operation of screw propellers:

$\mathrm{f}_{\text {IIIś1 }}=\mathrm{f}_{\mathrm{o}} / 1.77+\mathrm{f}_{\text {IÍs }}-3^{\text {rd }}$ harmonic frequency due to operation of one blade of screw propeller,

$\mathrm{f}_{\text {IIIś2 }}=2 \mathrm{f}_{\mathrm{o}} / 1.77+\mathrm{f}_{\text {IIśs }}-3^{\text {rd }}$ harmonic frequency due to operation of two blades of screw propeller,

$\mathrm{f}_{\text {IIIśs }}=4 \mathrm{f}_{\mathrm{o}} / 1.77+\mathrm{f}_{\text {IIśs }}-3^{\text {rd }}$ harmonic frequency due to operation of screw propeller.

3. Frequencies associated with rotation of shaft lines:

$\mathrm{f}_{\mathrm{LW} 1}=\mathrm{f}_{\mathrm{o}} /(2 * 1.77)$ - fundamental frequency due to rotation of shaft lines,

$\mathrm{f}_{\mathrm{LW} 2}=2 \mathrm{f}_{\mathrm{o}} /(2 * 1.77)-2^{\text {nd }}$ harmonic frequency due to rotation of shaft lines,

$\mathrm{f}_{\mathrm{LW} 3}=3 \mathrm{f}_{\mathrm{o}} /(2 * 1.77)-3^{\text {rd }}$ harmonic frequency due to rotation of shaft lines,

$\mathrm{f}_{\mathrm{LW} 4}=4 \mathrm{f}_{\mathrm{o}} /(2 * 1.77)-4^{\text {th }}$ harmonic frequency due to rotation of shaft lines;

where:

$\mathrm{f}_{\mathrm{o}} \quad-$ the fundamental frequency $\mathrm{f}_{\mathrm{o}}=\mathrm{n} / 60$,

$\mathrm{n}-$ number of rotations per one minute, $[\mathrm{rpm}]$,

s - stroke factor $(0.5$ - for four stroke engine),

1.77 - reduction ratio of ship reduction gear.

The calculation results obtained from the above given relationships are presented in Tab. 1.

The fundamental frequency resulting from unbalanced rotating elements of the main engines, $f_{0}=12.44[\mathrm{~Hz}]$, was determined with the use of B\&K PULSELABSHOP software. In an anlogous way were determined fundamental frequencies and their harmonics resulting from rotation of shaft lines $\left(\mathrm{f}_{\text {shaftline }}=7.03[\mathrm{~Hz}]\right)$. 
Tab. 1. Set of results obtained from the tests of the ship moving at the speed $v=4$ [kn] in dynamic trial area

\begin{tabular}{|c|c|c|}
\hline No. & $\mathbf{f}[\mathbf{H z}]$ & Frequencies of hydroacoustic wave sources \\
\hline 1. & 6.00 & Fundamental frequency of main engine firing (due to operation of one cylinder). \\
\hline 2. & 7.00 & $\begin{array}{l}\text { Fundamental frequency due to rotation of shaft lines. } \\
\text { Fundamental frequency due to operation of one blade of screw propellers }\end{array}$ \\
\hline 3. & 12.50 & Fundamental frequency of main engine firing (due to operation of two cylinders). \\
\hline 4. & 14.00 & $\begin{array}{l}2^{\text {nd }} \text { harmonic frequency due to rotation of shaft lines. } \\
\text { Fundamental frequency due to operation of two blades of screw propellers. }\end{array}$ \\
\hline 5. & 18.75 & Fundamental frequency of main engine firing (due to operation of three cylinders). \\
\hline 6. & 21.00 & $\begin{array}{l}3^{\text {rd }} \text { harmonic frequency due to rotation of shaft lines. } \\
\text { Fundamental frequency due to operation of three blades of screw propellers. }\end{array}$ \\
\hline 7. & 25.00 & Fundamental frequency of main engine firing (due to operation of four cylinders). \\
\hline I. & 25.25 & Fundamental frequency due to rotation of electric generating set \\
\hline 8. & 28.00 & Fundamental frequency due to operation of four blades of screw propellers. \\
\hline 9. & 31.00 & Fundamental frequency of main engine firing (due to operation of five cylinders). \\
\hline 10. & 35.25 & $2^{\text {nd }}$ harmonic frequency due to operation of single blades of screw propellers \\
\hline 11. & 37.25 & Fundamental frequency of main engine firing (due to operation of six cylinders). \\
\hline 12. & 42.25 & $2^{\text {nd }}$ harmonic frequency due to operation of two blades of screw propellers \\
\hline 13. & 43.50 & $2^{\text {nd }}$ harmonic frequency of main engine firing (due to operation of one cylinder). \\
\hline 14. & 49.25 & $2^{\text {nd }}$ harmonic frequency due to operation of three blades of screw propellers. \\
\hline 15. & 49.75 & $2^{\text {nd }}$ harmonic frequency of main engine firing (due to operation of two cylinders). \\
\hline 16. & 56.00 & $2^{\text {nd }}$ harmonic frequency of main engine firing (due to operation of three cylinders). \\
\hline 17. & 56.25 & $2^{\text {nd }}$ harmonic frequency due to operation of two blades of screw propellers. \\
\hline 18. & 62.00 & $2^{\text {nd }}$ harmonic frequency of main engine firing (due to operation of four cylinders). \\
\hline 19. & 63.25 & $2^{\text {nd }}$ harmonic frequency due to operation of three blades of screw propellers. \\
\hline 20. & 68.50 & $2^{\text {nd }}$ harmonic frequency of main engine firing (due to operation of five cylinders). \\
\hline 21. & 70.25 & $2^{\text {nd }}$ harmonic frequency due to operation of four blades of screw propellers. \\
\hline 22. & 74.75 & $2^{\text {nd }}$ harmonic frequency of main engine firing (due to operation of six cylinders). \\
\hline 23. & 81.00 & $3^{\text {rd }}$ harmonic frequency of main engine firing (due to operation of one cylinder). \\
\hline 24. & 87.00 & $3^{\text {rd }}$ harmonic frequency of main engine firing (due to operation of two cylinders). \\
\hline 25. & 93.25 & $3^{\text {rd }}$ harmonic frequency of main engine firing (due to operation of three cylinders). \\
\hline
\end{tabular}

The frequencies of sources of waves being components of acoustic field structure of the ship in question, presented in Fig. 5, were unambiguously attributed to ship's mechanisms and devices under operation. Results of the tests showed that to identify, in water environment, waves resulting from propulsion system operation, in the frequency band up to $100[\mathrm{~Hz}]$, is possible. The frequencies presented in Tab. 1 are in compliance with the theoretical relationships and measurement results obtained from the tests of the ship in the stationary trial area.
The insignificant differences in the particular frequencies of acoustic wave sources are caused by a little different rotational speeds of main engines. During the measurements the speeds was varying within the range from about 745 to about 760 [rpm].

The frequencies of operation of shaft lines and screw propellers obtained from the dynamic tests are also comparable with those obtained from the tests in the stationary trial area. The results are compared in Tab. 4. 
Tab. 2. Set of frequencies obtained from the tests conducted both in stationary and dynamic trial area

\begin{tabular}{|c|c|c|c|c|}
\hline \multirow{3}{*}{ Tests conducted in: } & \multicolumn{4}{|c|}{ Frequencies due to operation of main engine at the rotational speed $n=750[\mathrm{rpm}][\mathrm{Hz}]$} \\
\hline & \begin{tabular}{|c|} 
Left main engine \\
$f_{\text {fund }}=12.43[\mathrm{~Hz}]$ \\
(right M.E. -stopped)
\end{tabular} & $\begin{array}{c}\text { Right main engine } \\
f_{\text {fund }}=12.68[\mathrm{~Hz}] \\
\text { (left M.E. -stopped) }\end{array}$ & $\begin{array}{l}\text { Left main engine } \\
f_{\text {fund. }}=12.53[\mathrm{~Hz}]\end{array}$ & $\begin{array}{c}\text { Right main engine } \\
f_{\text {fund. }}=12.57[\mathrm{~Hz}]\end{array}$ \\
\hline & \multicolumn{2}{|c|}{ One propulsion system under operation } & \multicolumn{2}{|c|}{ Two propulsion systems under operation } \\
\hline the stationary trial area & $\begin{array}{l}12.50,18.75,24.75, \\
31.00,37.75,43.50 \\
49.75,56.00,62.25, \\
68.25,74.50,80.75, \\
87.00,93.25,99.50 .\end{array}$ & $\begin{array}{c}12.75,19.00,25.25 \\
31.75,38.00,44.25, \\
50.50,57.00,63.25 \\
69.50,76.00,82.25 \\
88.50,95.00\end{array}$ & $\begin{array}{c}12.50,18.75,25.00, \\
31.25,37.50,43.75, \\
50.25,56.50,62.75, \\
69.00,75.25,81.50, \\
87.75,94.00 .\end{array}$ & $\begin{array}{c}12.50,18.75,25.00, \\
31.50,37.75,44.00, \\
50.50,56.75,63.00, \\
69.25,75.50,81.75, \\
88.00,94.25 .\end{array}$ \\
\hline the dynamic trial area & \multicolumn{4}{|c|}{$\begin{array}{l}\text { 6.00, 12.50, 18.75, 25.00, } \\
31.00,37.25,43.50,49.75 \\
56.00,62,68.5,74.75 \\
81.00,87.00,93.25\end{array}$} \\
\hline
\end{tabular}

Tab. 3. Set of frequencies obtained from the trial area tests and theoretical relationships

\begin{tabular}{|l|c|c|}
\hline \multirow{2}{*}{ Source of hydroacoustic waves } & \multicolumn{2}{|c|}{ Frequencies of hydrodynamic waves } \\
\cline { 2 - 3 } & $\begin{array}{c}\text { obtained from the tests } \\
\text { in dynamic trial area }\end{array}$ & $\begin{array}{c}\text { calculated by using the presented } \\
\text { theoretical relationships }\end{array}$ \\
\hline \multirow{3}{*}{ Main engines } & $6.00,12.50,18.75,25.00$, & $6.22,12.44,18.66,24.88$, \\
& $31.00,37.25,43.50,49.75$, & $31.10,37.32,43.54,49.76$, \\
& $56.00,62.00,68.50,74.75$, & $55.98,62.20,68.42,74.64$, \\
& $81.00,87.00,93.25$. & $80.86,87.08,93.30$. \\
\hline \multirow{3}{*}{ Ship screw propeller and shaftline } & $7.00,14.00,21.00,28.00$, & $7.03,14.07,21.10,28.14$, \\
& $35.25,42.25,49.25,56.25$, & $35.17,42.20,49.24,56.27$, \\
& $63.25,70.25$. & $63.31,70.34$. \\
\hline
\end{tabular}

Tab. 4. Set of frequencies obtained from the tests conducted in dynamic trial area and standstill

\begin{tabular}{|l|l|c|c|c|}
\hline \multirow{3}{*}{ Tests conducted in: } & \multicolumn{4}{|c|}{$\begin{array}{c}\text { Frequencies due to operation of shaft lines and screw propellers at the main engines' } \\
\text { rotational speed } \mathbf{n}=\mathbf{7 5 0}[\mathrm{rpm}] \text { [Hz] }\end{array}$} \\
\cline { 2 - 5 } & $\begin{array}{c}\text { One propulsion system under operation } \\
\text { Two propulsion systems under operation }\end{array}$ \\
\cline { 2 - 5 } & $\begin{array}{c}\text { Left main engine } \\
\text { (Right M.E. } \\
\text { stopped) }\end{array}$ & $\begin{array}{c}\text { Right main engine } \\
\text { (Left M.E. -stopped) }\end{array}$ & Left main engine & Right main engine \\
\hline \multirow{2}{*}{ the stationary trial area } & \multicolumn{4}{|c|}{ Fundamental frequencies of shaft lines and screw propellers } \\
\cline { 2 - 5 } the dynamic trial area & $7.00,28.50$. & $7.25,28.50$. & $7.00,28.50$. & $7.00,28.50$. \\
\hline
\end{tabular}

The presented results of the tests made both in the dynamic and stationary trial area for the rotational speed of main engines, $\mathrm{n}=750[\mathrm{rpm}]$ in the band up to $100[\mathrm{~Hz}]$ showed that to identify the sources of waves in water environment is possible.

Identification of acoustic field structure of a ship on which two main engines operate at near rotational speeds but so much different that the characteristic components generated by left and right engine can be detected in the frequency spectrum, is a very complex problem. Occurrence of the components could be observed during the testing of acoustic field structure of the ship propelled by two main engines under operation at the rotational speed $\mathrm{n}=950[\mathrm{rpm}]$, and the propeller settings of $2^{\circ}, 2.5^{\circ}$ and $4.5^{\circ}$.
The ship with the above mentioned settings of its propeller developed the speed of $6,8,12[\mathrm{kn}]$, respectively. The spectrograms achieved during the tests are presented in Fig. 7.

When the ship was passing just over the sensors (the places distinguished by black lines in the spectrograms) the underwater noise spectra presented in Fig. 8, were recorded.

In the above presented figure the spectrum at the ship's speed of $8[\mathrm{kn}]$ was suppressed by $30[\mathrm{~dB}]$, and that at the speed of $12[\mathrm{kn}]$ - by $60[\mathrm{~dB}]$, in order to make their presentation more clear. The characteristic spectral components resulting from operating propulsion systems and electric generating sets appear at the same frequencies. From the analysis 
were obtained exact values of the fundamental frequencies associated with rotation of unbalanced movable elements of engines. The fundamental frequency of the left engine was: $\mathrm{f}_{\text {fund. }}=15.49[\mathrm{~Hz}](929[\mathrm{rpm}])$, and that of the right engine: $\mathrm{f}_{\text {fund. }}$ $=15.78[\mathrm{~Hz}](947[\mathrm{rpm}])$. Knowing rotational speed of the engines one can easily determine the remaining frequencies due to operation of the propulsion systems. Onto the spectra were introduced cursors - in black (for right engine) and in blue (for left engine) - associated with fuel oil combustion in the engines, as well as those in red - associated with operation of the screw propeller and shaft lines. In the spectra, above $30[\mathrm{~Hz}]$ frequency, one can observed double components reflecting differences in rotational speeds of the main engines to appear. To each component a successive number was attributed. The set of the excitations is presented together with their description in Tab. 5.

The tests performed on the ship moving at the speed $\mathrm{v}=6,8,12[\mathrm{kn}]$ in the dynamic trial area demonstrated that to identify, in water environment, acoustic waves resulting from operation of right and left propulsion system, is possible. The frequencies of sources of acoustic waves, experimentally obtained from the tests in the trial area, (Tab. 6), are in compliance with those calculated by using the theoretical relationships.

Tab. 5. Set of results obtained from the tests of the ship moving at the speed $v=6,8$ and 12 [kn], respectively, in dynamic trial area

\begin{tabular}{|c|c|c|}
\hline No. & f [Hz] & Frequencies of sources of hydroacoustic waves \\
\hline 1. & 8.00 & Fundamental frequency of main engine firing (due to operation of single cylinder of right and left engine). \\
\hline 2. & 8.75 & $\begin{array}{l}\text { Fundamental frequency of rotating shaft lines. } \\
\text { Fundamental frequency of operation of single screw propeller blade. }\end{array}$ \\
\hline 3. & 15.75 & Fundamental frequency of main engine firing (due to operation of two cylinders of right and left engine). \\
\hline 4. & 17.50 & $\begin{array}{l}\text { 2nd harmonic frequency of rotating shaft lines. } \\
\text { Fundamental frequency of operation of two screw propeller blades }\end{array}$ \\
\hline 5. & 23.25 & Fundamental frequency of main engine firing (due to operation of three cylinders of right and left engine). \\
\hline I & 25.25 & Fundamental frequency of electric generating set \\
\hline 6. & 26.25 & $\begin{array}{l}\text { 3rd harmonic frequency of rotating shaft lines - left propulsion system. } \\
\text { Fundamental frequency of operation of three screw propeller blades - left propulsion system. }\end{array}$ \\
\hline 7. & 26.50 & $\begin{array}{l}\text { 3rd harmonic frequency of rotating shaft lines - right propulsion system. } \\
\text { Fundamental frequency of operation of three screw propeller blades - right propulsion system. }\end{array}$ \\
\hline 8. & 31.25 & Fundamental frequency of main engine firing (due to operation of four cylinders of left engine). \\
\hline 9. & 31.50 & Fundamental frequency of main engine firing (due to operation of four cylinders of right engine). \\
\hline 10. & 35.00 & Fundamental frequency of operation of four screw propeller blades - left propulsion system. \\
\hline 11. & 35.50 & Fundamental frequency of operation of four screw propeller blades - right propulsion system. \\
\hline 12. & 38.75 & Fundamental frequency of main engine firing (due to operation of five cylinders of left engine). \\
\hline 13. & 39.50 & Fundamental frequency of main engine firing (due to operation of five cylinders of right engine). \\
\hline 14. & 46.50 & Fundamental frequency of main engine firing (due to operation of six cylinders of left engine). \\
\hline 15. & 47.25 & Fundamental frequency of main engine firing (due to operation of six cylinders of right engine). \\
\hline II & 50.25 & $2^{\text {nd }}$ harmonic frequency of electric generating set and supply network \\
\hline 16. & 54.25 & $2^{\text {nd }}$ harmonic frequency of main engine firing (due to operation of single cylinder of left engine). \\
\hline 17. & 55.25 & $2^{\text {nd }}$ harmonic frequency of main engine firing (due to operation of six cylinders of right engine). \\
\hline 18. & 62.00 & $2^{\text {nd }}$ harmonic frequency of main engine firing (due to operation of six cylinders of left engine). \\
\hline 19. & 63.00 & $2^{\text {nd }}$ harmonic frequency of main engine firing (due to operation of two cylinders of right engine). \\
\hline 20. & 69.75 & $2^{\text {nd }}$ harmonic frequency of main engine firing (due to operation of three cylinders of left engine). \\
\hline 21. & 71.00 & $2^{\text {nd }}$ harmonic frequency of main engine firing (due to operation of three cylinders of right engine). \\
\hline 23. & 78.75 & $2^{\text {nd }}$ harmonic frequency of main engine firing (due to operation of four cylinders of right engine). \\
\hline 24. & 85.25 & $2^{\text {nd }}$ harmonic frequency of main engine firing (due to operation of five cylinders of left engine). \\
\hline 25. & 86.75 & $2^{\text {nd }}$ harmonic frequency of main engine firing (due to operation of five cylinders of right engine). \\
\hline 26. & 93.00 & $2^{\text {nd }}$ harmonic frequency of main engine firing (due to operation of six cylinders of left engine). \\
\hline 27. & 94.50 & $2^{\text {nd }}$ harmonic frequency of main engine firing (due to operation of six cylinders of right engine). \\
\hline
\end{tabular}


Ship's speed of $6[\mathrm{kn}]$ at the propeller setting of $2^{\circ}$

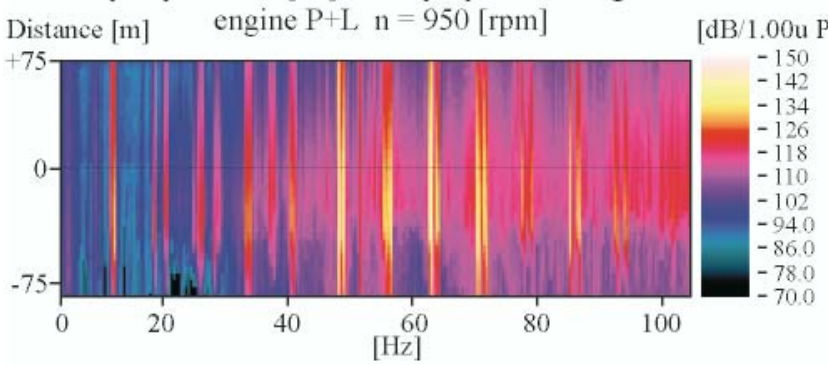

Ship's speed of $8[\mathrm{kn}]$ at the propeller setting of $2.5^{\circ}$ Distance $[\mathrm{m}] \quad$ engine $\mathrm{P}+\mathrm{L} \mathrm{n}=950[\mathrm{rpm}]$

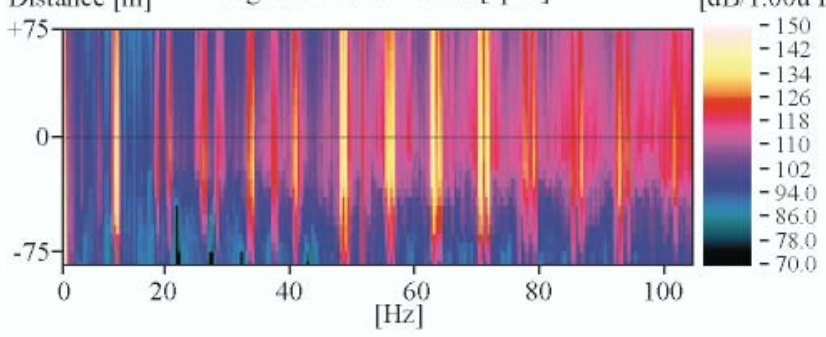

Ship's speed of $12[\mathrm{kn}]$ at the propeller setting of $4.5^{\circ}$ Distance $[\mathrm{m}] \quad$ engine $\mathrm{P}+\mathrm{L} \mathrm{n}=950[\mathrm{rpm}]$

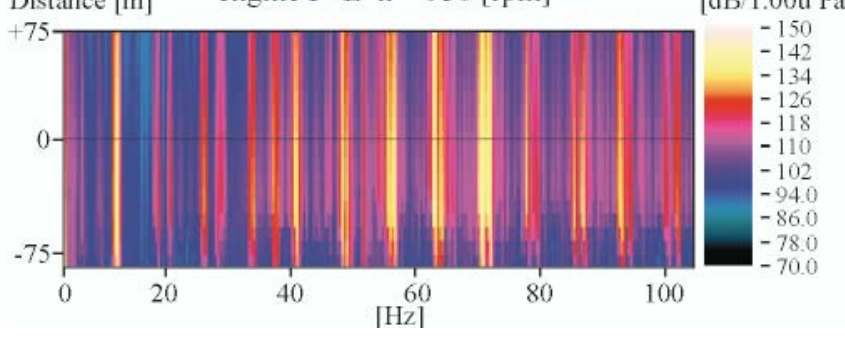

Fig. 7. Spectrograms achieved during the tests in dynamic trial area, at the rotational speed of main engines $n=950[\mathrm{rpm}]$ and the propeller setting of $2^{\circ}, 2.5^{\circ}$ and $4.5^{\circ}$, respectively

\section{CONCLUSIONS}

- As has been demonstrated in this publication, to identify hydroacoustic waves associated with operation of ship propulsion systems and auxiliary mechanisms is possible also in shallow water.

- The comprehensive tests conducted in measurement trial areas (both movable and stationary) demonstrated that on the basis of underwater noise measurements it is generally possible to identify, in ship hydroacoustic field structure, its characteristic components associated with operation of main engines, shaft lines and screw propellers as well as those resulting from operation of electric generating sets.

- The used identification method of hydroacoustic waves, consisting in simultaneous measuring vibrations and acoustic pressure, has made it possible to exactly determine frequencies of the waves. Knowing the frequencies appearing in the considered band up to $100[\mathrm{~Hz}]$ one is able to unambiguously attribute them to a given propulsion system, and on this basis to determine type of a considered ship.

- The elaborated theoretical relationships have been confirmed by the results of the tests. Differences between the experimentally obtained results and those calculated by using the given relationships have not exceeded $0.25[\mathrm{~Hz}]$, it means that the determined error has been contained in the frequency band of the filters applied to processing the signals.

- In the future a series of comprehensive tests should be performed with the aim of determining maximum distances at which identification of particular ships would be still possible. The tests should be conducted in a coastal acoustic station both in various sea state conditions and various noise levels of hydroacoustic background, and also in trial areas located in Gdansk Bay at various water depths.

Tests in dynamic trial area

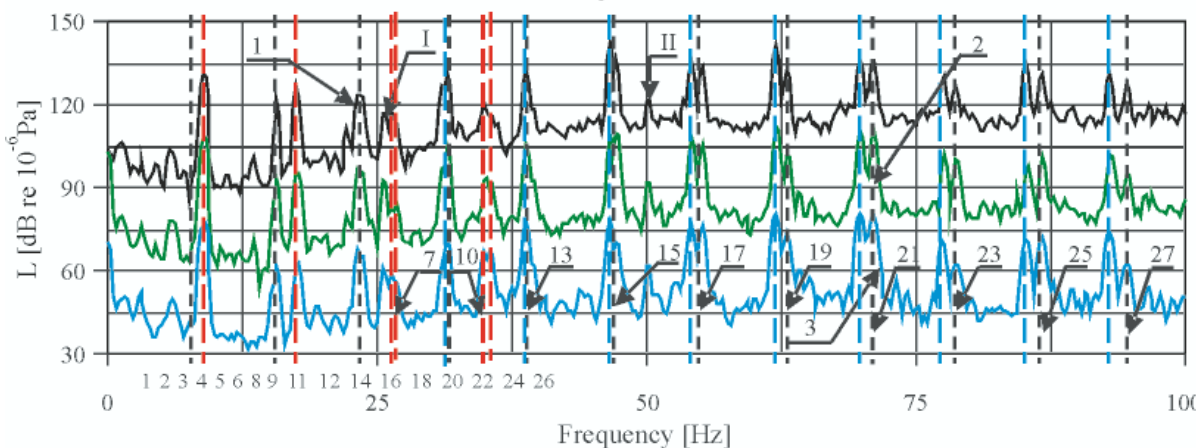

Fig. 8. Underwater noise spectra recorded during the tests in dynamic trial area at the rotational speed of main engines $n=950$ [rpm].

Notation: 1. the tests made at the ship's speed $v=6[\mathrm{kn}]$ and the propeller setting of $2^{\circ}, 2$. the tests made at the ship's speed $v=8$ [kn] and the propeller setting of $2.5^{\circ}$ (signal suppressed by $30[\mathrm{~dB}]$ ), 3. the tests made at the ship's speed $v=12$ [kn] and the propeller setting of $4.5^{\circ}$ (signal suppressed by 60 [dB]

Tab. 6. Set of frequencies obtained from the trial area tests and theoretical relationships

\begin{tabular}{|c|c|c|}
\hline \multirow[b]{2}{*}{ Source of hydroacoustic waves } & \multicolumn{2}{|c|}{ Frequencies of hydroacoustic waves } \\
\hline & $\begin{array}{l}\text { obtained from the tests in } \\
\text { dynamic trial area }\end{array}$ & $\begin{array}{l}\text { calculated by using the presented } \\
\text { theoretical relationships }\end{array}$ \\
\hline Right main engine & $\begin{array}{c}8.00,15.75,23.50,31.50,39.50 \\
47.25,55.25,63.00,71.00,78.75 \\
86.75,94.50\end{array}$ & $\begin{array}{c}7.89,15.78,23.67,31.56,39.45 \\
47.34,55.23,63.12,71.01,78.90 \\
86.79,94.68\end{array}$ \\
\hline Left main engine & $\begin{array}{c}8.00,15.75,23.50,31.25, \\
38.75,46.50,54.25 .62 .00,69.75 \\
77.50,85.25,93.00\end{array}$ & $\begin{array}{c}7.75,15.49,23.24,30.98,38.73 \\
46.47,54.22,61.96,69,71,77.45 \\
85.20,92.94\end{array}$ \\
\hline Screw propeller and right shaftline & $8,75,17.50,26.50,35.50$ & $8.92,17.84,26.76,35.68$ \\
\hline Screw propeller and left shaftline & $8,75,17.50,26.25,35.00$ & $8.76,17.51,26.27,35.03$. \\
\hline
\end{tabular}




\section{BIBLIOGRAPHY}

1. Baranowska A Gloza I.: Identification of underwater disturbance sources by using coherence functions (in Polish). Materials of $48^{\text {th }}$ Open Seminar on Acoustics, pp. $245 \div 250$, Wrocław 2001.

2. Gloza I., Malinowski S.: Identification of ships underwater noise sources in the coastal region. Hydroacoustics, Vol. 5/6, 9-16, 2003.

3. Gloza I., Domagalski J., Malinowski S.: Identification of ships hydro-acoustic field sources in the near surrounding (in Polish), Materials of $49^{\text {th }}$ Open Seminar on Acoustics, pp. 407-412, Warszawa - Stare Jabłonki 2002.

4. Grelowska G., Bittner P., Gloza I.: Experimental tests of noise generated by ship in motion (in Polish). Materials of $9^{\text {th }}$ Seminar on Hydro-acoustics, pp. 125-132, Gdynia-Jurata, 1992.

6. R. J. Urick: Principles of Underwater Sound, Mc Graw - Hill, New York 1975

7. Kozaczka E., Domagalski J., Gloza I.: Investigation of the underwater noise produced by ships by means of intensity method, Polish Maritime Research No 3(66) 2010 Vol 17

8. E. Kozaczka, I. Gloza, Measurement of underwater noise produced by means of the intensity method, Proceedings of EURONOISE 2009, Edinburgh, UK, 26-28 October 2009

9. E. Kozaczka, I. Gloza, Determination of the ship signature in the very shallow water, Proceedings of the 14th International Congress on Sound and Vibration, Cairns, 9-12 July 2007, 6 pp., CD

10.E. Kozaczka, G. Grelowska, Shipping noise, Archives of Acoustics vol. 29, 2, 169-176, (2004)

11.E. Kozaczka, S. Kozaczka, Classification of underwater objects by means of an acoustic method, Proceedings of the 13th International Congress on Sound and Vibration, Vienna, Austria, 2-6 July 2006

\section{RESEARCH REPORTS}

1. Kozaczka E, Kiciński W., Milanowski W.: Identification tests of acoustic signals emitted into water environment, Stage II Gdynia 1993.

2. Kozaczka E., Grelowska G., Bittner P., Baranowska A.,: Experimental tests of ship hydro-acoustic field, Stage III Gdynia 1993.
3. Kozaczka E., Grelowska G., Bittner P., Baranowska A., Kiciński W., Milanowski W.: Spatial distribution of underwater noise emitted by ships to hemisphere, and its normalization Gdynia 1997.

4. Kozaczka E., Grelowska G., Bittner P., Baranowska A., Milanowski W., Dobrzaniecki J.: Spatial distribution of underwater noise emitted by ships to hemisphere, Stage II, Gdynia 1992.

5. Kozaczka E., Grelowska G., Gloza I., Dobrzaniecki J., Przysowa T.: Passive acoustic observation of coastal zone with the use of broad-band acoustic characteristics of ships, Gdynia 1997.

6. Kozaczka E., Kiciński W., Nyszko G.: Identification tests of acoustic signals emitted into water environment, Stage II Gdynia 1995

7. Kozaczka E., Kiciński W., Nyszko G.: Identification tests of acoustic signals emitted into water environment, Stage IV Gdynia 1995.

The research presented in this paper has been conducted with the support of the projects No. 0047/R/T00/2009/08 and No. 0089/R/T00/2009/09 of the Polish Ministry of Science and Higher Education.

\section{CONTACT WITH THE AUTHORS}

Eugeniusz Kozaczka, Prof., Faculty of Ocean Engineering and Ship Technology

Gdansk University of Technology Narutowicza 11/12

80-233 Gdansk, POLAND fax: (058) 347-21-81, e-mail: kozaczka@pg.gda.pl

Jacek Domagalski, Ph. D.

Faculty of Navigation and Naval Waeapons,

Polish Naval Academy Śmidowicza 69

81-103 Gdynia POLAND 